ISSN: 0213-2087 e-ISSN: 2444-7080

DOI: https://doi.org/10.14201/shhcont372019319345

\title{
LA IDEA DE ESPAÑA DE ALFONSO OSORIO: UN «PROYECTO NEOFORALISTA» EN LOS PRIMEROS GOBIERNOS DE LA TRANSICIÓN ${ }^{1}$
}

\section{The idea of Spain of Alfonso Osorio: a «neoforalist projects in the first governments of the transition}

\author{
Adrián MAGALDI FERNÁNDEZ \\ Universidad de Cantabria
}

RESUMEN: Este artículo pretende analizar la figura de Alfonso Osorio y la idea de España que mantuvo durante los años de la transición democrática, estudiando los proyectos que trató de llevar a cabo para abordar el problema territorial. La cuestión ha sido analizada a través de un acercamiento biográfico al personaje, para lo cual ha sido de especial valor el diverso material depositado en su archivo personal, así como el testimonio del propio Osorio y otros copartícipes de su experiencia vital. Esto ha permitido conocer las líneas principales de su pensamiento, que en este artículo ha sido definido como "neoforalista". Desde esta concepción trató de llevar a cabo diversos proyectos que, sin embargo, chocaron con la posición mantenida por Adolfo Suárez, sin una idea definida al respecto y partidario de postergar la cuestión, siendo las diferentes concepciones del hecho regional una de las causas de la ruptura política entre ambos personajes.

Palabras clave: Alfonso Osorio; transición democrática; neoforalismo; País Vasco; Cataluña.

ABSTRACT: This article aims to analyze the figure of Alfonso Osorio and the idea of Spain that he maintained during the years of the democratic transition, studying the projects he tried to carry out to address the territorial problem. The issue has been approached

1. Este trabajo se enmarca en el proyecto financiado por la Agencia Estatal de Investigación y por el Fondo Europeo de Desarrollo Regional: «La razón biográfica: biografías y narraciones autobiográficas en la investigación histórica y literaria del s XX europeo. Estudios de caso y reflexión teórica». HAR2017-82500-P (AEI/ FEDER/ UE) 
through a biographical analysis, for which the diverse material deposited in his personal archive has been of special value, as well as the testimony of Osorio and other partners of his life experience. This has made it possible to know the main lines of his political thought, which, in this article, has been defined as «neoforalist». From this conception he tried to carry out different projects that, nevertheless, clashed with the position of Adolfo Suárez, without a definite idea of this problem and in favor of relegating the issue, being the different conceptions of the regional fact one of the causes of the political rupture between both politicians.

Key words: Alfonso Osorio; democratic transition; neoforalism; Basque Country; Catalonia.

\section{INTRODUCCIÓN}

Según Rodolfo Martín Villa habría sido Torcuato Fernández-Miranda el primero en referirse a la Transición como una gran obra teatral en la cual el Rey sería el empresario, el propio Fernández-Miranda el guionista y Adolfo Suárez su actor principal². Este símil ha sido repetido en numerosas ocasiones para referirse a los grandes protagonistas del período, dejando a un lado el papel jugado por la sociedad o al resto de actores políticos que asumieron cargos de responsabilidad durante los años del cambio político. Un lugar destacado ocuparía una de las figuras que podemos mencionar entre los grandes olvidados de la Transición: Alfonso Osorio. Siguiendo con el modelo de FernándezMiranda, Osorio habría sido el "coprotagonista», en tanto que vicepresidente político del Gobierno, y el encargado de buscar «el elenco principal» de aquella obra, puesto que la mayoría de los ministros del primer gobierno de Suárez fueron «reclutados» por Osorio, dando lugar a lo que los mentideros madrileños de la época bautizaron como «un gobierno Osorio presidido por Suárez»³.

Nacido en Santander en 1923, Alfonso Osorio había ocupado diversos cargos de segundo nivel durante el franquismo: procurador en Cortes, miembro del Consejo del Reino, subsecretario de Comercio entre 1965 y 1968, y presidente de RENFE de 1968 a 1970. Procedente de las filas de la ACNP (Asociación Católica Nacional de Propagandistas), Osorio estaba vinculado a los sectores católicos del régimen, y pronto se mostró como una de las figuras más importantes del sector reformista desde una posición democristiana conservadora. Monárquico confeso, fue su proximidad al entorno de Zarzuela lo que permitió que, en el primer gobierno formado tras la muerte de Franco, todavía con Carlos Arias Navarro como presidente, Alfonso Osorio fuera nombrado ministro de la Presidencia. Cuando en julio de 1976 Adolfo Suárez llegó a la jefatura del Gobierno, fue confirmado en la cartera de Presidencia y ascendido a vicepresidente político, cargos que ocupó hasta la remodelación ministerial llevada a cabo tras

2. MARTín VILLA, Rodolfo: Al servicio del Estado. Barcelona: Planeta, 1984, p. 50.

3. Guadiana, 13 de julio de 1976. 

EN LOS PRIMEROS GOBIERNOS DE LA TRANSICIÓN

las primeras elecciones democráticas del 15 de junio de 1977. Durante ese tiempo, colaboró estrechamente con Suárez en la tramitación con éxito de la reforma política. Según Marcelino Oreja, ministro de Asuntos Exteriores en aquel gobierno, Suárez y Osorio formaron «un auténtico tándem [...] Suárez tenía una cosa muy importante, tenía intuición y tenía valor, pero no tenía mucha sustancia, y él completaba eso con Alfonso" . También la periodista Victoria Prego señala cómo "Alfonso Osorio fue para Adolfo Suárez un elemento irrenunciable. Alfonso Osorio fue la pata solvente de Adolfo Suárez en lo jurídico y en lo políticons.

Sin embargo, progresivamente fueron surgiendo diferencias entre ambos líderes políticos. Osorio discrepó de Suárez sobre la forma en que se tramitó la legalización del Partido Comunista, o en la decisión de incluir un sector socialdemócrata en UCD (Unión de Centro Democrático), el partido gubernamental configurado para respaldar la candidatura de Suárez en las elecciones. Pero, especialmente, el choque entre ambos se produjo por la forma en que se abordó la cuestión territorial. Según el propio Alfonso Osorio, «esa es una de las discrepancias por las que yo no podía seguir con Adolfo Suárez" ${ }^{6}$. Osorio mantenía unas firmes convicciones sobre la necesidad de reconocer el hecho regional, de acuerdo con la realidad histórica y los elementos diferenciales existentes, como base sobre la cual afianzar la unidad nacional. Se trataba de una posición "neoforalista», tal y como se explicará a lo largo de este artículo, que contrastaba con la visión del presidente Suárez, para quien el problema territorial se trataba de un tema secundario, en parte por un cierto desconocimiento de la materia, pero, fundamentalmente, por ser un elemento secundario dentro de su proyecto de reforma política, centrada en la democratización de las instituciones y en la realización de unas elecciones libres. La diferente concepción de dicha cuestión provocó diversos choques ideológicos entre ambos políticos, lo cual contribuyó a distanciarlos en sus objetivos e intereses.

Osorio fue, durante el primer gobierno de Adolfo Suárez, la figura con un proyecto más definido, y quien más insistió, respecto a la necesidad de afrontar la organización territorial del Estado. Este artículo pretende analizar el pensamiento político de Alfonso Osorio respecto a la vertebración nacional de la España postfranquista, así como las diversas iniciativas que emprendió al respecto. Para ello se partirá del estudio de los proyectos regionales planteados por el reformismo tardofranquista para, a continuación, centrar el análisis en las propuestas de Osorio y ver su reflejo durante sus años en el gobierno, especialmente en lo relativo al País Vasco y Cataluña, así como los choques que sus tesis tuvieron con las ideas de Adolfo Suárez.

\footnotetext{
4. Entrevista a Marcelino Oreja, 6 de junio de 2017.

5. Entrevista a Victoria Prego 16 de mayo de 2017.

6. Entrevista a Alfonso Osorio, 27 de mayo de 2016.
} 


\section{La descentralización Reformista. El caso de Alfonso Osorio}

El régimen franquista había mantenido desde sus inicios una rigurosa centralización del Estado bajo la idea de una España unida y uniforme. Durante los últimos años de la dictadura, mientras los sectores más ortodoxos del franquismo continuaban defendiendo tales planteamientos, los grupos reformistas incluyeron entre sus diversas demandas acerca de la transformación del Estado, la necesidad de abordar una cierta descentralización y regionalización del país, la cual fue abordada desde tres posicionamientos:

En primer lugar, se situarían aquellas tesis nutridas de lo que Xosé Manoel Núñez Seixas ha definido como un nacionalismo español regionalizado ${ }^{7}$. Serían los sectores que, aún aceptando el reconocimiento cultural de las regiones, representado en sus tradiciones, folclores, paisajes y pueblos; carecían de auténticos proyectos acerca de un reconocimiento jurídico-administrativo del hecho regional, manteniéndose en unas proclamas y postulados bastante imprecisos. Un ejemplo claro lo observamos en la figura del propio Adolfo Suárez y la asociación política que presidió durante el tardofranquismo, la Unión del Pueblo Español (UDPE). En sus estatutos, UDPE apenas se refería a «una acción que permita el desarrollo de las peculiaridades culturales, sociales y económicas de todas las regiones españolas dentro del ámbito de la unidad nacional», sin definir el trasfondo de dicha problemática ${ }^{8}$.

En segundo lugar, se encontraría un regionalismo funcionalista basado en criterios técnicos, con los cuales se pretendía poner fin a los desequilibrios territoriales. Esta visión bebía de las aportaciones llegadas desde el mundo académico a través de las teorías de Gunnar Myrdal, la geografía del desarrollo territorial, y el análisis económico regional9 ${ }^{9}$. El ejemplo más claro fue el proyecto planteado en 1973 por el entonces ministro para la Planificación del Desarrollo, Cruz Martínez Esteruelas, quien sugirió la división de España en 14 regiones siguiendo parámetros economicistas. No obstante, fueron muchas las alternativas construidas, procedentes mayoritariamente de diseños realizados desde el mundo universitario, como fueron las propuestas de Manuel Casas Torres (según desarrollo económico), José Isbert Soriano (por actividad productiva), Román Perpiñá Grau (según estructura de la renta), o Juan Hortalá (de acuerdo con el bienestar social $)^{10}$.

Por último, en tercer lugar, estaría el regionalismo político-historicista. Desde estos planteamientos se pretendía alcanzar una notable descentralización político-administrativa a través de unas regiones configuradas a partir de vínculos históricos y la existencia de

7. NÚÑEZ, Xosé Manoel: «El nacionalismo español regionalizado y la reinvención de identidades territoriales, 1960-1977", Historia del presente, 13, 2009, pp. 55-70.

8. UDPE: Memoria y estatutos. Madrid, 1975.

9. NÚÑEZ, Xosé Manoel: «El nacionalismo español ...op.cit., p. 60.

10. Informaciones, 31 de marzo de 1973. 

EN LOS PRIMEROS GOBIERNOS DE LA TRANSICIÓN

una conciencia diferenciadora. Defensores firmes de la unidad nacional, consideraban en cambio que debía abandonarse la idea uniformista y centralista del franquismo, para dotar a los diversos territorios del Estado de unas competencias y organismos propios $^{11}$. Ejemplo claro de estas tesis era la posición defendida por el grupo Tácito, entre cuyos miembros más destacados figuraba Alfonso Osorio.

Tácito surgió en 1973 como un grupo de pensamiento de tendencia democristiana partidario de una democratización del Estado, manifestando sus ideas a través de diversos editoriales que, semanalmente, se difundían a través del diario $\mathrm{Ya}^{12}$. Su primer artículo, publicado el 23 de junio de 1973 bajo el título «Declaraciones, propósitos, realizaciones», teorizó acerca de las diversas reformas que, en su opinión, debía llevar a cabo el régimen franquista para una democratización del Estado, refiriéndose, entre otras, a la importancia de afrontar el problema de la organización territorial. De este modo, se indicaba:

El riesgo del regionalismo en España ha sido siempre el cantonalismo, al que se llega cuando las tendencias centrífugas de la periferia prevalecen sobre las fuerzas centrípedas de la unidad nacional.

Pero es evidente también que la concentración total de los poderes en una instancia central suprema y única, cuando lleva consigo la pérdida absoluta de toda intervención de las regiones, conduce a la paradójica situación de que al efecto disgregador de los separatistas de la periferia se añada el efecto igualmente nocivo de los que actúan, sin quererlo, como separadores del centro ${ }^{13}$.

Perfilada, en su primer artículo, la necesidad de afrontar la cuestión regional, tres semanas después, Tácito publicó un artículo dedicado, íntegramente, al fenómeno regional, en el cual apuntaban:

No parece ocioso proclamar como punto de partida que la unidad nacional constituye para nosotros un fenómeno irreversible. Cualquier enunciado que atente contra la misma, además de anticonstitucional, resultaría gravemente anacrónico al nivel al que —con todas sus imperfecciones - ha llegado nuestra convivencia. Nos referimos, naturalmente, a una conciencia de unidad que no puede concebirse de modo uniformista, centralizador y desconocedor de las peculiaridades propias de las distintas partes de nuestro territorio ${ }^{14}$.

A continuación, Tácito manifestaba la obligación de abordarse una auténtica descentralización que "no debe ser un poder organizado burocráticamente desde una cuadrícula de gabinete, sino que debe partir de la realidad viva. Esta realidad viva no

11. POWELL, Charles: «El reformismo centrista y la Transición democrática: retos y respuestas», Historia y política, 18, 2007, pp. 58-59.

12. Entrevista a Alfonso Osorio, 4 de marzo de 2016.

13. Ya, 23 de junio de 1973.

14. Ya, 10 de julio de 1973 . 
es otra que la marcada por las regiones históricas, muy difíciles de fragmentar atendiendo a criterios de eficacia o de oportunidad", una crítica frontal a las posiciones apoyadas por el regionalismo funcionalista ${ }^{15}$. Frente a las propuestas llegadas desde el ámbito académico, Tácito defendía «el reconocimiento a las regiones de un auténtico "poder» propio, no delegado del estatal, sino traspasado por esta con un conjunto de competencias y unos organismos específicos ostentadores de ese poder ${ }^{16}$. Posteriormente se matizaba que «el grado de desarrollo variará de una u otra región, desde el momento en que no es impuesto, sino que se nutre de abajo a arriba, de una vitalidad, conciencia de personalidad propia y, en definitiva, grado de madurez social de cada una de las regiones», por lo que estimaban indispensable prestar una atención especial hacia aquellos territorios que partieran de unas mayores peculiaridades, como serían los casos vaco y catalán ${ }^{17}$.

Estas tesis del grupo Tácito, reflejo de ese regionalismo político-historicista, representan de forma clara las líneas fundamentales del pensamiento de Alfonso Osorio acerca de la regionalización del Estado. El político santanderino se trataba de uno de los miembros del grupo que concedía mayor relevancia a la materia, y con unas ideas más concretas al respecto. Estas se nutrían, principalmente, de dos fuentes: el principio de subsidiaridad extraído del personalismo cristiano y, de especial modo, los postulados procedentes del pensamiento tradicionalista, con los que Osorio mantenía, en este terreno, unas ciertas afinidades ideológicos e, incluso, de carácter biográfico ${ }^{18}$. Aunque nacido en la ciudad de Santander, y desde joven vinculado al entorno de Acción Católica y la ACNP, Osorio descendía de una familia de orígenes carlistas y procedencia transmerana, de la localidad de Bárcena de Cicero, situada en las proximidades de Cantabria con el País Vasco. Todo esto permitió un cierto poso ideológico tradicionalista en su pensamiento que se reflejó en aspectos como lo relativo a su idea de España. En su defensa de los derechos históricos vascos, Osorio no dudaba en señalar las similitudes entre ciertas tradiciones vascas y las llevadas a cabo en la propia zona de Trasmiera, donde bajo una encina, en Hoz de Anero, se reunieron durante siglos las juntas de la Merindad de Transmiera para tratar los asuntos de la comarca ${ }^{19}$. Estos vínculos biográficos con el mundo tradicionalista se reforzaron tras su matrimonio con María Teresa Iturmendi, hija de Antonio Iturmendi, político carlista de orígenes vascos que ocupó cargos destacados durante el franquismo, como el Ministerio de Justicia o la Presidencia

15. Ibid.

16. Ibid.

17. Ibid.

18. Las afinidades ideológicas de Osorio con el tradicionalismo deben ser limitadas al hecho regional, ya que en otros ámbitos sus postulados políticos van a estar visiblemente influidos por la doctrina social de la Iglesia, debiéndolo calificar como un democristiano conservador.

19. Entrevista a Alfonso Osorio, 27 de mayo de 2016. 

EN LOS PRIMEROS GOBIERNOS DE LA TRANSICIÓN

de las Cortes. Estas afinidades con el entorno tradicionalista forjaron en Alfonso Osorio una idea de España influida por los postulados mantenidos desde el tradicionalismo, configurando una línea de pensamiento que, a lo largo de este artículo, será referida como «neoforalista», y cuyos ejes vertebradores se expondrán a continuación.

La idea de España de Alfonso Osorio partía de la apuesta por una considerable descentralización que tuviera, como punto de partida, "las regiones históricas" y la existencia de una conciencia diferenciadora, criticando abiertamente las propuestas del regionalismo funcionalista. Según declaró en una conferencia pronunciada el 2 de abril de 1975 en el Círculo de Economía de Barcelona, era indispensable «devolver a las regiones su personalidad histórica", añadiendo que

nuestro país no tiene que inventarse el hecho regional; tan solo tiene que dar vida de derecho a un hecho que es histórico. España no tiene que copiar los modelos de regionalización que se han puesto en marcha en la Comunidad Europea. Nosotros tenemos nuestras regiones, aunque en estado de hibernación ${ }^{20}$.

Declarándose inspirado por el pensamiento regionalista vazquezmellista, reivindicaba las regiones desde una defensa de "la variedad en la unidad», concibiendo el reconocimiento del hecho regional como una forma de asegurar la nación. Para el político santanderino, "la regionalización es el reconocimiento de un hecho cierto e innegable, la variedad de los pueblos, las culturas, las tradiciones y las lenguas de esa unidad de destino histórico que es España, no es separatismo ni nacionalismo; es el reverso del nacionalismo» ${ }^{21}$. Esto le llevaba a elogiar la figura y postulados regionalistas mantenidos por Juan Vázquez de Mella, por lo que no dudaba en rechazar el legado del siglo XIX, asegurando que

no fueron los hombres de la izquierda de entonces, aquellos que levantaban la bandera del liberalismo político e ideológico, quienes tuvieron sensibilidad para este problema. Fueron los hombres de la derecha más enraizada en la tradición como don Juan Vázquez de Mella, ya en los primeros años del siglo XX, los que pusieron de manifiesto que España, para ser unitaria, tenía que ser plural; para mantenerse como nación, tenía que ser diversa. [...]

Si se hubiesen respetado desde el poder central las libertades, los fueros y las autonomías regionales, no hubiesen surgido los fenómenos separatistas ${ }^{22}$.

Osorio criticaba abiertamente los proyectos centralizadores del siglo XIX, que consideraba no habían respetado las conciencias diferenciadoras y tradiciones de las diversas regiones, suponiendo un problema para la unidad nacional. Igualmente se distanciaba

20. Conferencia "La regionalización de España", disponible en: OSORIO, Alfonso: Escrito desde la derecha. Barcelona: Plaza y Janés, 1985, pp. 175-188.

21. Ibid.

22. Ibid. 
de las propuestas federalistas que, en su opinión, significaban reconocer una soberanía propia de los territorios, según la cual, el Estado se habría configurado como parte de un acuerdo voluntario. Desde su visión, esa unión de las regiones era previa al Estado, un hecho histórico que remontaba a época de los Reyes Católicos, pues, «nosotros los españoles, adjetivados vascos o catalanes, aragoneses o castellanos, estamos al llegar a estas cinco centurias, voluntariamente juntos, asociados en deslumbrantes empresas o convivencia en momentos amargos, pero prosiguiendo un similar destino» ${ }^{23}$. Continuando con sus apelaciones al pensamiento vazquemellista, lo que se observa en Osorio es la contraposición ya realizada por el pensador tradicionalista, quien confrontaba «la federación revolucionaria» con "la federación histórica» representada por su proyecto regional ${ }^{24}$. Sería esta última una federación de regiones a las cuales se las reconocería su personalidad y facultades, pero que no surgiría de un mero pacto voluntario, sino de una unión histórica simbolizada por la monarquía. Nuevamente se percibe en Osorio la influencia vazquezmellista con la idea de una "monarquía federativa», así como en su visión organicista de la nación, en la que haciendo suya la metáfora del pensador tradicionalista, la nación era un río cuyos afluentes serían las regiones ${ }^{25}$. Para Osorio, no debía olvidarse que «España no es sino una Nación de viejos reinos» ${ }^{26}$.

Osorio abogaba de este modo por un reconocimiento de la región que fuera más allá de una "desconcentración administrativa». Según su criterio, las regiones debían gozar de una cierta autonomía económica y reglamentaria, ya que "las instituciones de ámbito regional pueden tener facultades para establecer su propia normativa en algunos aspectos ${ }^{27}$. Como declaraba en una entrevista concedida a La Vanguardia en abril de 1975, «la regionalización implica descentralización de poderes, autonomía, autogestión y, por tanto, su reconocimiento como unidad de decisión", indicando, consecuentemente, la obligación de avanzar hacia «regiones que tengan [en un futuro] garantizada su existencia por la Constitución y que aun estando privadas de poder

23. $A B C, 12$ de mayo de 1972 .

24. SEVILLA, Francisco: Sociedad y regionalismo en Vázquez de Mella. Madrid: Actas Editorial, 2009.

25. Sobre la idea de la monarquía como nexo de las diferentes regiones de España, es un claro ejemplo la propuesta realizada por Osorio en 1969, cuando Juan Carlos fue designado sucesor de Franco. Ante la imposibilidad de usar el título de Príncipe de Asturias, que suponía vincular su nombramiento a la sucesión dinástica, y la necesidad de encontrar un nuevo nombre, Alfonso Osorio propuso el título de "Príncipe de las Españas", alegando el uso histórico que de este título se habría realizado en época de los Austrias, así como por la simbología que tenía de acuerdo con su idea de España como monarquía federativa. Su propuesta fue aceptada, aunque se decidió limitar el título a Príncipe de España, perdiendo el carácter con que había sido concebida por Osorio. Entrevista a Alfonso Osorio, 4 de marzo de 2016. VILALLONGA, José Luis: Franco y el Rey. La espera y la esperanza. Barcelona: Plaza y Janés, 1998, p. 192.

OSORIO, Alfonso: Escrito desde... op.cit.

26. Ibid.

27. La Vanguardia, 3 de abril de 1975. 

EN LOS PRIMEROS GOBIERNOS DE LA TRANSICIÓN

constituyente se rijan por su propio Estatuto, otorgado por el Estado pero elaborado en la propia Región»28. Así, concluía apostando por un reconocimiento de las diversas regiones de España, apuntando que

para mi es necesario establecer un regionalismo generalizado a todo el país y que por supuesto no sea una simple desconcentración administrativa. Además, hay que tener presente que la acentuación del hecho diferencial en algunas regiones, hasta ahora, ha producido un recelo en otras regiones y ha sido contrario a la puesta en práctica de un auténtico programa regionalista. Por todo ello considero que es preciso generalizar el fenómeno de la regionalización del país, lo que no quiere decir que no se preste especial atención a aquellas regiones que tienen unas peculiaridades específicas ${ }^{29}$.

Las regiones que Osorio estimaba necesario abordar de acuerdo con unos rasgos propios eran las provincias vascas y Cataluña, no contemplando en ningún caso la especificidad de Galicia, donde a pesar de su proyecto estatutario durante la II República y contar con unos rasgos históricos y culturales propios, opinaba que no existía una conciencia diferenciadora lo suficientemente arraigada en la población ${ }^{30}$. Respecto a la peculiaridad vasca, Osorio apelaba a unos derechos históricos que sería necesario recuperar, en referencia al régimen foral perdido en 1876, así como al concierto económico que, después de la guerra civil, sólo había conservado Álava, ya que Vizcaya y Guipúzcoa se habían visto privadas de él por no alinearse durante el conflicto con el autoproclamando «bando nacional». En lo referido al caso catalán, sus posturas aparecen, inicialmente, más difuminadas, dada la dificultad de traducir esos derechos históricos en una realidad política concreta ante la ausencia de una manifiesta tradición foralista, ya que la pérdida de Cataluña de sus leyes se remontaba a los Decretos de Nueva Planta. Osorio acabó por vincular la singularidad catalana a la restauración de la institución de la Generalitat, bajo su forma configurada durante la II República, pero con un nuevo estatuto. No obstante, en el pensamiento osorista dicha institución se vinculaba directamente con aquella perdida durante la Guerra de Sucesión. La Generalitat suponía la forma de reconocer, según los términos aplicados por Miguel Herrero de Miñón, unos «derechos históricos tácitos» con los cuales poder vincular a sus planteamientos pactistas aquellas comunidades histórico-políticas que ofrecían mayores dificultades de una articulación teórica concreta ${ }^{31}$. El resto de regiones,

28. Ibid.

29. Ibid.

30. Entrevista a Alfonso Osorio, 27 de mayo de 2016.

31. Miguel Herrero de Miñón, otro destacado protagonista de la Transición, puede ser igualmente vinculado a esa línea neoforalista, con unos proyectos de similares bases y objetivos a los planteados por Osorio. No obstante, mientras en Osorio se percibe un trasfondo más claramente historicista y con una evidente influencia del tradicionalismo, Herrero de Miñón sumaba a esa visión historicista unas formulaciones teóricas más definidas, como la idea de los fragmentos de Estado de Jellinek. La diferencia más obvia entre 
preveía se constituyeran de acuerdo con su tradición histórica, sin llegar a plantear un mapa en concreto, para posteriormente dotarse de una base normativa propia elaborada desde dichos territorios ${ }^{32}$.

Estas eran las líneas básicas del pensamiento «neoforalista» planteado públicamente por Osorio durante los últimos años de la dictadura. De ello dejó constancia a través de su participación en Tácito, en las diversas ponencias y entrevistas realizadas, así como en la asociación política que, en marzo de 1975, promovió junto al exministro Federico Silva, la Unión Democrática Española (UDE). Dicha asociación hizo de la defensa del reconocimiento de las regiones unas de sus líneas definitorias e, incluso, la sección catalana se configuró como una entidad autónoma federada, Unió Catalana, presidida por Santiago Udina ${ }^{33}$. Se revelaba cómo el fenómeno regional constituía una de las piezas fundamentales en el proyecto reformista que, para Osorio, debía llevarse a cabo una vez se produjera lo que eufemísticamente venía denominándose como «el hecho biológico inevitable».

\section{Los proyectos de REgionalización de AlFonso Osorio}

\subsection{Alfonso Osorio, ministro de la Corona}

Tras la muerte de Franco y la posterior coronación de Juan Carlos I como Rey de España el 22 de noviembre de 1975, se llevó a cabo una remodelación ministerial tras la cual Osorio se incorporó como ministro de la Presidencia en el primer gobierno de la monarquía. Durante este último ejecutivo dirigido por Arias Navarro, que se prolongó hasta inicios del verano de 1976, Osorio todavía no actuó sobre el problema territorial. El tema fue asumido por Manuel Fraga, vicepresidente para Asuntos Políticos, quien el 20 de febrero de 1976 puso en marcha una comisión para estudiar la creación de un indefinido «régimen administrativo especial» para las cuatro provincias catalanas,

ambos era que, mientras en el pensamiento de Osorio se observaba una referencia a la politerritorialidad, para él existía una única nación, España; en cambio, Herrero de Miñón creía en la plurinacionalidad del Estado, refiriéndose a Cataluña y Euskadi como naciones. Sobre la idea de España de Miguel Herrero de Miñón, véase: HERRERO DE MIÑÓN, Miguel: Memorias de estío. Madrid: Temas de hoy, 1993, y HERRERO DE MIÑÓN, Miguel: Derechos históricos y Constitución. Madrid: Taurus, 1998.

32. En el pensamiento de Osorio no aparece ninguna mención concreta al caso navarro. Se deduce por sus ideas que también sopesara dotar a Navarra de ciertas singularidades de acuerdo con sus derechos históricos, derivándose la ausencia de menciones al caso navarro de la falta de un conflicto político en esta región que, además, no había perdido sus singularidades bajo la dictadura debido a su alineamiento con la España franquista durante la guerra civil.

33. CONTE, Jesús: Las asociaciones políticas. Barcelona: ATE, 1976, pp. 151-154. Sobre la UDE, véase: MAGALDI, Adrián: "Alfonso Osorio y la Unión Democrática Española (UDE): un proyecto democristiano en transición", Aportes, 97, 2018, pp. 233-266. 

EN LOS PRIMEROS GOBIERNOS DE LA TRANSICIÓN

siguiendo el modelo que ya se estaba analizando para el caso de las provincias de Vizcaya y Guipúzcoa desde el 7 de noviembre de $1975^{34}$.

Cuando Osorio comenzó verdaderamente a actuar al respecto fue a partir de julio de 1976, después del nombramiento de Adolfo Suárez como presidente del Gobierno y su propio ascenso a vicepresidente político. Al asumir la presidencia, Suárez realizó diversas declaraciones en las que afirmaba su voluntad de afrontar el problema nacional y regional, pero su actuación se limitó a simples proclamas. Como señala María Cristina Sánchez-Mateos, durante todo su primer gobierno, "Suárez se mantiene en una ambigüedad constante al no especificar las características de dicho proceso de cambio [territorial], sino que sólo se limita a afirmarlo para mantener el equilibrio entre los que abogan por una centralización total y los que defienden la descentralización por completo»35. Suárez decidió proseguir con las comisiones constituidas por Fraga y optó por centrar su política en la reforma institucional, relegando el problema territorial a un segundo plano. Además, en Suárez se sumaba un cierto desconocimiento sobre la materia al partir de unas posiciones nutridas de ese nacionalismo español regionalizado que carecía de un proyecto auténticamente definido al respecto. Osorio se trataba de una de las pocas voces dentro del gabinete que insistió en abordar el fenómeno regional, tan solo recibiendo el apoyo del ministro de Hacienda, Eduardo Carriles, y de Marcelino Oreja quien, debido a sus competencias en materia internacional, apenas pudo influir en la materia ${ }^{36}$.

Osorio insistía en priorizar la problemática territorial y abordar el asunto antes de las primeras elecciones, debido a tres motivos. En primer lugar, por su propia convicción ideológica al respecto, y la posibilidad de vincular dichas regiones al Estado a través de la monarquía, pues si el asunto era relegado, serían los partidos políticos quienes capitalizaran los éxitos de la descentralización. En segundo lugar, el temor a la pérdida del control sobre el proceso democratizador por parte del reformismo, ante los posibles resultados electorales que obtendrían la izquierda y los nacionalistas en los primeros comicios. Osorio mostraba sus recelos hacia unos partidos de izquierdas que, en su oposición al centralismo franquista, habían integrado en sus programas reivindicaciones

34. MOLINERO, Carme: "Los primeros gobiernos de la monarquía y la cuestión catalana». En: REDERO SAN ROMÁn, Manuel (ed.): Adolfo Suárez y la Transición Política. Salamanca: Ediciones Universidad de Salamanca, 2017, pp. 145-153.

35. SÁNCHEZ-MATEOS, María Cristiana: "La idea de nación española a través de los discursos de Adolfo Suárez, 1976-1978». En: GONZÁLEZ, Damián, ORTIZ, Manuel, PÉREZ, Juan Sisinio (eds.): La Historia, lost in translation?. Cuenca: Universidad de Castilla-La Mancha, 2017, p. 201.

36. Al igual que en el caso de Osorio, en las posiciones de Carriles y Oreja tuvieron una fuerte influencia las razones biográficas. Eduardo Carriles Galarraga, aunque santanderino de nacimiento, tenía unos orígenes maternos que le relacionaban con el País Vasco. Por su parte, Marcelino Oreja Aguirre procedía de una familia vasca vinculada al tradicionalismo, y su propio padre, Marcelino Oreja Elósegui, había sido diputado tradicionalista durante la II República. 
de los nacionalismos periféricos. Además, tanto socialistas como comunistas apelaban en aquellos momentos al derecho a la autodeterminación, tesis heredada de las luchas anticoloniales de los años 60, si bien entendido como la capacidad de cada territorio de determinar libremente sus relaciones con los diferentes pueblos de España en un marco territorial común, bajo la forma de una república federal, y recuperando los estatutos de autonomía de la II República ${ }^{37}$. También mostró sus temores hacia los planteamientos de la oposición moderada, con un Equipo Demócrata Cristiano del Estado Español cuyos líderes, Joaquín Ruíz-Giménez y José María Gil-Robles, se habían visto arrastrados hacia planteamientos federales por los socios nacionalistas de la coalición: el Partido Nacionalista Vasco y Unió Democràtica de Catalunya. En último lugar, Osorio revelaba su preocupación ante un posible descontrol del proceso debido a las crecientes demandas procedentes de las antiguas élites regionales y locales del franquismo, que habían visto en la bandera de los intereses regionales la forma de legitimarse y perpetuarse ante el nuevo contexto político ${ }^{38}$. Estos neorregionalismos lo preocuparon especialmente, ya que una de las regiones donde este fenómeno se mostró de una forma más contundente fue en su Santander natal.

Todos estos motivos le llevaron a insistir en la necesidad de precisar un programa regional con el que abordar la organización territorial del Estado. Osorio decidió plantear un proyecto de regionalización, nutrido en cierto modo del entonces famoso Informe Crowther-Kilbrandon británico que, en 1973, había propuesto un modelo de descentralización regional para Reino Unido $^{39}$. A imitación de este, en aquellas regiones con una especial identidad histórico-cultural, en su opinión Cataluña y País Vasco, se aplicaría una amplia descentralización y se reconocerían unas instituciones y leyes propias de acuerdo con su tradición histórica. Esto se traducía en la restauración de la Generalitat en Cataluña, y el régimen foral en las provincias vascas, operación que a su entender debían ser capitalizadas por la Corona. Por su parte, en el resto del territorio nacional se articularían diferentes gobiernos regionales, según criterios históricos, a los cuales preveía llegar a través de un reforzamiento de las diputaciones provinciales y la creación de diputaciones regionales configuradas a partir de varias provincias. Estos gobiernos regionales, preveía fueran presididos por un "gobernador regional» que sería

37. JULIÁ, Santos: "Nación, nacionalidades y regiones en la transición política a la democracia”. En: MORENO, Javier (ed.): Izquierdas y nacionalismos en la España contemporánea. Madrid: Editorial Pablo Iglesias, 2011: pp. 274-275; y QUIROGA, Alejandro: "Coyunturas críticas. La izquierda y la idea de España durante la Transición", Historia del presente, 13, 2009, p. 25.

38. NÚNEZ, Xosé Manoel: "Inventar la región, inventar la nación: acerca de los neorregionalismos autonómicos en la España del último tercio del siglo XX». En: SABIO, Alberto, FORCADELL, Carlos (coords.): Las escalas del pasado: IV Congreso de Historia Local de Aragón (Barbastro, 3-5 de julio de 2003). Huesca: I.E.A., 2005, p. 54.

39. CUADRADO, Juan Ramón: "El informe Crowther-Kilbrandon y el desarrollo de las propuestas de financiación regional en el Reino Unido", Revista de documentación administrativa, 179, 1978, pp. 41-86. 

EN LOS PRIMEROS GOBIERNOS DE LA TRANSICIÓN

elegido en las urnas, no contemplando en ningún caso la existencia de algún tipo de cámara legislativa. Dichas «diputaciones» contarían con una importante descentralización administrativa y una limitada capacidad legislativa en cuestiones que pudieran ser mejor tratadas desde el propio territorio, como determinadas competencias en materia de infraestructuras o algunos temas de gestión económica ${ }^{40}$. Según José Manuel Otero Novas, en esos momentos subsecretario técnico de Presidencia, Osorio llegó a entregar a Suárez un estudio con dicha propuesta, pero este no lo prestó mayor atención ${ }^{41}$.

A parte de este proyecto, Osorio dedicó una importante actuación política para tratar aquellos casos que más le preocupaban, como eran los relativos al País Vasco, Cataluña y su tierra de Santander.

\subsection{El caso cántabro}

La situación de la todavía provincia de Santander se trató de uno de los casos que más angustió a Osorio dados sus vínculos biográficos con esta región. En la provincia había surgido un incipiente movimiento autonomista liderado por el hasta entonces delegado del Sindicato Vertical en Torrelavega, Miguel Ángel Revilla, quien había fundado en abril de 1976 la Asociación para la Defensa de los Intereses de Cantabria (ADIC). Esta organización reivindicaba la identidad y particularidades propias de Santander, pidiendo su separación de Castilla y un concierto económico para una región que pasaban a denominar Cantabria ${ }^{42}$. La propuesta del nombre de Cantabria fue bien recibida por Osorio, aceptando las raíces históricas de ese nombre que, ya durante el franquismo, se había tratado de recuperar a través de una iniciativa promovida en 1963 por el entonces presidente de la diputación provincial, Pedro Escalante ${ }^{43}$. Sin embargo, rechazaba frontalmente los planteamientos de separación de Castilla, inserto en una visión claramente castellanista debido a sus tesis historicistas y al peso que el castellanismo tenía entre los sectores de la burguesía santanderina a la cual pertenecía ${ }^{44}$.

En julio de 1976, al poco tiempo de asumir la vicepresidencia, Osorio recibió en Madrid a los principales dirigentes de ADIC, a quienes mostró su rechazo tanto a su

40. Entrevista a Alfonso Osorio, 6 de mayo de 2016.

41. OTERO, José Manuel: Lo que yo viví. Barcelona: Prensa Ibérica, 2015, p. 409.

42. SANZ, Julián: «La Transición, de la Dictadura a la Monarquía Parlamentaria (1975-1982)». En: AA.VV.: Historia de Cantabria. Tomo III. Santander: Editorial Cantabria, 2007, p. 60.

43. MARTínEZ, Gonzalo: Fueros sí, pero para todos. Madrid: Silos, 1976, pp. 145-150.

44. La burguesía santanderina se había construido, mayoritariamente, a partir del comercio con América del trigo llegado de Castilla. Esta vinculación económica creada desde mediados del siglo XVIII contribuyó a afianzar entre las clases altas de Santander una relación identitaria entre Castilla y su provincia. Véase: SUÁREZ, Manuel: Casonas hidalgos y linajes. La invención de la tradición cántabra. Santander: Universidad de Cantabria, 1994. 
demanda de un concierto económico como a una posible separación de Castilla ${ }^{45}$. Esto le valió numerosas críticas desde ADIC, aunque Osorio tampoco escapó de los ataques de la parte castellanista, con una Alianza Regional de Castilla y León (ARCL) que, en un intento por homologarse con las provincias vascas, solicitó un concierto económico, pero, en su caso, para una futura región de Castilla y León compuesta por once provincias, entre las cuales estaría Santander ${ }^{46}$. Este modelo había sido propuesto por uno de los principales promotores de la asociación, el medievalista Gonzalo Martínez, catedrático de historia del derecho en la Universidad de Valladolid. Martínez había publicado obras como «Fueros sí, pero para todos», desde cuyas páginas demandaba una generalización de los conciertos económicos y defendía una Castilla que calificaba como la mayor víctima del centralismo, criticando que «ningún antecedente histórico puede servir de justificación a la injusticia fiscal», por lo que estimaba que «la mejor y única garantía de que un concierto económico es justo será el que esté abierto a todas las provincias» ${ }^{47}$. A pesar de que Osorio pudiera coincidir con los planteamientos castellanistas de ARCL sobre las provincias que debían comprender la futura región castellana - mantenía dudas sobre la posibilidad de vertebrar una región leonesa-, desde sus posiciones «neoforalistas» consideraba que en dichas provincias no existía una tradición histórica que legitimara un concierto económico propio. Únicamente aceptaba que esta región fuera dotada en un futuro de una base normativa propia en la que pudiera incluirse competencias de gestión económica en ciertas materias que fuera preferible gestionar desde la propia región. Esta posición hizo que fuera duramente criticado por miembros de ARCL, como su presidenta en Santander, Carmen Cossío, quien manifestó públicamente su deseo de "partirle una vara de avellano en la cabeza a Alfonso Osorio", a quien acusaba de no preocuparse de los problemas de Santander ${ }^{48}$.

Durante su etapa como vicepresidente, Osorio hizo todo lo posible por frenar estas demandas, pero, tras la aprobación de la Constitución, la provincia de Santander consiguió alcanzar una autonomía propia. Su actuación respecto a Cantabria se debió, básicamente, a los vínculos biográficos y emocionales que le unían con esta región; siendo en realidad los casos vasco y catalán a los que dedicó mayores esfuerzos.

\subsection{El caso vasco}

En las provincias vascas, Osorio juzgaba imprescindible actuar para que Vizcaya y Guipúzcoa restablecieran sus derechos históricos, perdidos tras un decreto de junio

45. ALEGRÍA, Manuel: Presencia e influencia de ADIC en historia de Cantabria. Santander: Edición Tantín, 1990, p. 51.

46. GONZÁLEZ, Mariano: "Alianza Regional: Un primer intento regionalista en Castilla y León (19751977)", Investigaciones históricas: Época moderna y contemporánea, 21, 2001, p. 323

47. OSORIO, Alfonso: Cantabria, un nombre propio. Madrid: Casa de Cantabria, 1984, p. 3.

48. Informaciones, 13 de junio de 1977. 

EN LOS PRIMEROS GOBIERNOS DE LA TRANSICIÓN

de 1937 como castigo a su oposición a la sublevación franquista. Durante la dictadura, las diputaciones vizcaína y guipuzcoana habían tratado de recuperarlos, pero lo único que consiguieron fue que, en 1968, fueran suprimidas las expresiones más ofensivas del decreto abolitorio, pero su carácter sancionador se mantuvo ${ }^{49}$. Llegada la Transición, la situación vasca apenas había vivido modificaciones, y los resultados de las comisiones para el estudio de un régimen administrativo especial para ambas provincias no habían realizado avances significativos. Desde el ejecutivo, Osorio abogó por derogar el decreto abolitorio y que las provincias costeras vascas recuperasen sus derechos forales, tanto en el terreno económico como administrativo, llegando a plantear la conveniencia de que fuera el propio rey quien acudiera a Guernica para actuar como «los viejos Reyes de Castilla» y realizar dicha devolución ${ }^{50}$. Osorio aseguró haber propuesto esta operación a Adolfo Suárez que, aconsejado por Torcuato Fernández-Miranda, la habría desechado ${ }^{51}$.

Pese a las reticencias iniciales del presidente, gracias al apoyo de otros miembros del ejecutivo, como Carriles y Oreja, Osorio consiguió que Suárez realizara algunas concesiones. El 30 de octubre de 1976 fue derogado el decreto abolitorio, aunque ello no supuso la recuperación del concierto económico para Vizcaya y Guipúzcoa, y en su lugar se estableció una mera descentralización del gasto y del ingreso por medio de la transferencia de impuestos dentro de una unidad fiscal del país ${ }^{52}$. Meses después, el 4 de marzo de 1977, se restablecieron las Juntas Generales, todavía con un diseño poco preciso al formarse a partir de ayuntamientos no democráticos. Pero a Osorio, estas medidas le parecían insuficientes, y abogaba por un reconocimiento expreso de los derechos históricas vascos, y que dichas provincias avanzasen hacia una autonomía efectiva sin esperar a un proceso constituyente, a lo que Suárez mostraba su oposición. Además, Osorio juzgaba que otras decisiones estaban siguiendo un rumbo equivocado, como era la cuestión de la ikurriña, cuyo uso fue tolerado, que no legalizado, el 19 de enero de 1977, lo que al santanderino le pareció una posición ambigua. Él propuso regular su uso y reconocimiento por parte de los entes correspondientes, junto a otras banderas de uso regional y local, encontrando nuevamente el rechazo del Presidente a tales propuestas ${ }^{53}$.

49. ALONSO, Eduardo: "El largo camino para la recuperación del concierto económico de Vizcaya y Guipúzcoa, 1968-1981». En: AA.VV.: Historia de la transición y la consolidación democrática en España . Vol. I. Madrid: UAM, 1995, pp. 385-388.

50. VAN-HALEN, Juan: Objetivo: ganar el futuro (Conversaciones con Alfonso Osorio). Barcelona: Plaza y Janés, 1986, p. 176.

51. Entrevista a Alfonso Osorio, 1 de abril de 2016.

52. ALONSO, Eduardo: ...op.cit., p. 402.

53. A esta diferencia sobre las limitaciones que, en su opinión, suponía la forma en que se había tramitado el uso de la ikurriña en las tres provincias vascas, parecía sumarse su discrepancia a que Navarra fuera incluida entre los territorios que regularían su uso. Esta era una medida a la que había accedido Rodolfo Martín Villa, ministro de Gobernación, tras una reunión con el Grupo de Alcaldes, colectivo de 
Pese a todas las discrepancias, el terreno en que las diferencias entre Suárez y Osorio se reflejaron más nítidamente fue la forma en que debía ser abordado el problema etarra. Para Suárez, resolver el conflicto terrorista era primordial para encauzar la situación en el País Vasco, mientras Osorio consideraba que se trataban de dos conflictos diferentes y era crítico hacia cualquier concesión al entorno de ETA. La nueva amnistía aprobada por el gobierno el 11 de marzo de 1977, y la posterior decisión del 20 de mayo de proceder al extrañamiento de diversos presos etarras, fueron valoradas por Osorio como simples cesiones a la banda terrorista que en nada contribuían a solventar el conflicto vasco. Especialmente crítico se mostró con el extrañamiento del mes de mayo, ya que según relató el político santanderino, el mismo día que el consejo de ministros se reunió para tomar aquella decisión,

nos llegó la noticia del secuestro de Javier Ibarra, y cuando esta información se puso sobre la mesa, y fui yo el que lo hice porque casualmente había salido del salón para hacer una llamada telefónica y me encontré con otra de la Dirección General de Seguridad en la que se nos daba la noticia, la reacción de Adolfo Suárez fue: «No puede ser ETA». Le parecía imposible que ETA [...] pudiese, aquel mismo día que se procedía al extrañamiento de los hombres de ETA, proceder al secuestro de Javier Ibarra ${ }^{54}$.

Lo cierto es que Ibarra, conocido empresario y antiguo alcalde de Bilbao, había sido secuestrado por comandos berezi y apareció asesinado al poco tiempo ${ }^{55}$. Del mismo modo en que Osorio se oponía a dichas medidas, también reconocía que «nunca fui partidario de la negociación con ETA", por lo que permaneció distante de las relaciones que se establecieron con miembros de la banda terrorista ${ }^{56}$. El 20 de diciembre de 1976, agentes del SECED se reunieron en el Hotel du Khóne de Ginebra con miembros de ETA político-militar, que «implícitamente» aceptaron una tregua, y de ETA militar, reacia a concesiones y partidaria de mantenerse en las líneas descritas en la Alternativa KAS ${ }^{57}$.

Osorio criticaba que las medidas llevadas a cabo no estaban siendo las realmente necesarias para resolver la situación vasca, marcando distancias con un Suárez que

regidores procedentes de movimientos sociales vasquistas que habían protagonizado un cierto entrismo en las instituciones locales del tardofranquismo. URRUTIA, Txema: Alcaldes en lucha. El grupo de Bergara en la transición, 1975-1979. Tafalla: Txalaparta, 2006. ÁLVAREZ, Eduardo: El problema vasco en la transición democrática española (1975-1979). Acción política y competencia entre identidades. Tesis doctoral dirigida por José Álvarez y Gonzalo Álvarez. Universidad Complutense de Madrid, 2018, pp. 216-217.

54. VAN-HALEN, Juan: ... op.cit., p. 176.

55. Los comandos berezi se trataba de una escisión de ETA-pm crítica con los procesos de negociación y tregua entablados con el gobierno, por lo que acabó sumándose a las filas de ETA-m.

56. VAN-HALEN, Juan: ... op.cit., p. 176.

57. La Alternativa KAS se trató de un programa de mínimos detallado por la izquierda abertzale en julio de 1976 que, entre otras medidas, incluía las demandas de amnistía, libertades democráticas, disolución de "los cuerpos represivos" o reconocimiento de la soberanía nacional de Euskadi, con la posibilidad de crear un Estado propio. Sobre las negociaciones con ETA: Archivo Otero Novas (AON), caja 15, carp. 11. 

EN LOS PRIMEROS GOBIERNOS DE LA TRANSICIÓN

parecía limitar la cuestión a un problema de orden público. En su diario personal, lamentaba que

Suárez no entiende el problema del País Vasco. Piensa que, al hablarle de la restitución de los derechos económicos forales, por mi boca se exponen viejas ideas tradicionalistas y que defiendo a los capitalistas vascos que no quieren pagar impuestos. Cree que el problema es ETA y la tozudez vasca y no percibe que, para luchar eficazmente con aquella, lo primero es tener un gesto de buena voluntad, un gesto justo, con el pueblo vasco ${ }^{58}$.

Así, sus propuestas en favor del reconocimiento del régimen foral y las singularidades históricas vascas, que consideraba fundamentales para canalizar la problemática situación del País Vasco, se vieron reducidas a simples intentos que debieron esperar a la redacción de la Constitución para una actuación real sobre el asunto.

\subsection{El caso catalán}

Fue el problema territorial existente en Cataluña al que Osorio dedicó mayores esfuerzos durante su año como vicepresidente del Gobierno. En palabras del propio Osorio, «fui un convencido de que resolver el problema de Cataluña era resolver el problema de España, de la Monarquía y de la democracia "59. Consideraba que encauzar la situación en Cataluña sería clave para una correcta vertebración nacional antes del previsible escenario político que se abriría tras las elecciones democráticas. Orientó sus objetivos hacia la restauración de la Generalitat, institución que estimaba de un evidente valor histórico y simbólico para el pueblo de Cataluña, a través de su presidente en el exilio, Josep Tarradellas, poniendo en marcha la operación para su retorno. Según Miguel Herrero de Miñón, «esa operación quien la lanzó y la hizo posible fue Osorio ${ }^{60}$. Este pretendía recuperar la institución en su forma republicana, pero dotada de una nueva base normativa con la cual vincularla a la monarquía, permitiendo así una reconciliación de dicha institución con la dinastía de los Borbones.

Los primeros contactos con Tarradellas se habían iniciado ya en época de Carlos Arias Navarro, cuando Manuel Fraga envió a su hombre de confianza en Cataluña, Manuel Milián Mestre, a reunirse con Tarradellas en su exilio de Saint-Martin-le-Beau. Sin embargo, al político gallego tan sólo le interesaba la legitimidad que la figura de Tarradellas podía aportar a sus proyectos de reforma, y ante las primeras dificultades desistió de esa operación en favor de la propuesta de unos regímenes administrativos especiales para las provincias catalanas ${ }^{61}$. Realmente, fue el 3 de noviembre de 1976

58. OSORIO, Alfonso: De orilla a orilla. Barcelona: Plaza y Janés, 2000, p. 209.

59. VAN-HALEN, Juan: ... op.cit., p. 118.

60. Entrevista a Miguel Herrero de Miñón, 5 de abril de 2017.

61. MOLINERO, Carme, e YSÀS, Pere: La cuestión catalana. Cataluña en la transición española. Barcelona: Crítica, 2014, p. 59. 
cuando la operación se inició, con motivo de la reunión entre Osorio y el empresario catalán Manuel Ortínez, a quien conocía de sus años como subsecretario de Comercio cuando este era director general de moneda extranjera. La visita se debía a los deseos de Ortínez de informarle sobre sus contactos con Josep Tarradellas y plantearle la posibilidad de restablecer la Generalitat. Según Ortínez, su restauración permitiría dar salida a las crecientes reivindicaciones autonómicas catalanas con una institución de un manifiesto valor histórico e identitario para el pueblo catalán. Osorio se mostró favorable a la idea y le pidió que sondeara a Tarradellas sobre la posibilidad de recuperar la Generalitat y reconocer su legitimidad a cambio de que acatara públicamente la Corona, la unidad de España, y manifestara su respeto al ejército ${ }^{62}$. Después de que Ortínez visitara nuevamente a Tarradellas para sugerirle esa propuesta, este volvió a reunirse con el vicepresidente el 10 de noviembre, transmitiéndole la aceptación de Tarradellas, en líneas generales, a la proposición planteada. Osorio, quien había sondeado con éxito su proyecto ante algunos líderes políticos catalanes, como Joan Mas Cantí y Carlos Güell, decidió presentarle a Suárez las posibilidades de dicha operación ${ }^{63}$. Inicialmente, el presidente mostró reparos a la propuesta, en especial hacia la figura de Tarradellas, alegando su avanzada edad y sus largos años fuera de España, en un exilio que podría haberlo distanciado de la realidad catalana. Suárez era partidario de contar con un político como Jordi Pujol, opción apoyada por Salvador Sánchez-Terán, gobernador civil de Barcelona, y Rodolfo Martín Villa, ministro de la Gobernación y antiguo gobernador civil de Barcelona, años en los que había entablado una cierta relación con Pujol ${ }^{64}$. Pero Osorio insistió en el valor de la figura de Tarradellas, frente a un Pujol que se trataba de un hombre de partido con escaso capital simbólico. Finalmente, Suárez accedió a enviar al teniente coronel Andrés Casinello, jefe de los servicios informativos de presidencia y hombre de su confianza, para que se reuniera con Tarradellas y dialogara con este con autorización directa del gobierno.

El 26 de noviembre se produjo dicha reunión en la casa de Tarradellas a las afueras de París, tras lo cual Casinello elaboró un amplio informe que hizo llegar a Suárez y Osorio, en cuyo archivo se encuentra depositado íntegramente. Dicho documento se inicia con una detallada descripción de la situación en que se encontraba el presidente de la Generalitat en el exilio, indicando que

Tarradellas irradia dignidad. Tiene algo de unción sacerdotal o de paternidad. Todo le viene de una lejana historia y así los acontecimientos nuevos son siempre, para él, recuerdo de otros ya superados. [...] Hay que meterse en su casa, donde todo es pobreza,

62. OSORIO, Alfonso: Trayectoria politica de un ministro de la Corona. Barcelona: Planeta, 1980, pp. 319-320.

63. Ibid: 320 .

64. GONZÁLEZ, Carlos: «Instituciones históricas y cambio político: el restablecimiento de la Generalitat de Cataluña (1977)», Historia Contemporánea, 53, 2015, p. 667. 

EN LOS PRIMEROS GOBIERNOS DE LA TRANSICIÓN

para entender su dignidad. La Banca Catalana le montaría un palacio, pero él vive en una llanura fría del centro de Francia, con una calefacción tibia, sin baño, con muebles que ya no usan los suboficiales y solo el lujo de una buena biblioteca y un tocadiscos. Únase una hija subnormal y una esposa callada. No hay criados, ni secretarios, nada.

A ese hombre lo nombran Presidente y durante 20 años nadie le hace caso. Pero ahora van los arzobispos, los banqueros, los políticos de todas las clases a saludarle y llamarle presidente. Posiblemente pocos quieren obedecerle, aunque todos busquen su refrendo $[\ldots]$

Conmueve verlo, oírle o discutir con él. Vale para una tragedia. Al final lo que desea es entrar en Barcelona y que los mozos de escuadra le rindan honores. Después querrá morirse. Es como un rey destronado hablando de la dinastía y de la corona ${ }^{65}$.

A continuación, se precisaban sus posiciones respecto a la cuestión catalana, indicando que «Tarradellas quiere la institución, la generalidad» $\mathrm{y}$ «se niega a constituir un gobierno en el exilio" ${ }^{66}$. Seguidamente, se expresaba cómo el político catalán "no quiere que el Gobierno pacte con los grupos [políticos]. Quiere ser el intermediario, el protagonista. Piensa que su autoridad moderará las posturas, que su institución salvará el enfrentamiento entre Cataluña y el resto de España ${ }^{67}$. Finalmente, se indicaba la posición de Tarradellas respecto al resto de regiones del país, explicándose que este «no es federal. Los problemas de las otras regiones (País Vasco, Galicia, etc...) no le afectan en absoluto y quedará siempre al margen de los planteamientos valencianistas y mallorquines ${ }^{68}$. Se trataba esta de una visión que no hacía sino confirmar a Osorio en su propuesta, al ver en Tarradellas una figura que no estaba dispuesta a la generalización federalista propugnada desde amplios sectores de la oposición, y que además estaba interesado en llevar adelante el proceso de restauración de la Generalitat evitando la influencia de los partidos políticos, hacia cuyas posiciones Osorio mostraba ciertos recelos.

Esta toma de contacto exitosa permitió que Osorio planteara el desarrollo jurídicoadministrativo para la restauración de la Generalitat, y llegara incluso a pensar en la posibilidad de una operación similar en el País Vasco con Jesús María de Leizaola, lehendakari en el exilio. La base normativa para restaurar la Generalitat partiría de la derogación del decreto de 1938, por el cual se había anulado el régimen autonómico de Cataluña, para dar paso a una «mancomunidad de las cuatro Diputaciones Catalanas, que, en atención a los [...] antecedente históricos y tradiciones se llamará Generalidad»,

65. Archivo Alfonso Osorio (AAO): Informe sobre la entrevista de Casinello con Tarradellas 1976-1977. El AAO se encuentra sin clasificar, lo que impide una referencia más detallada.

66. Ibid.

67. Ibid.

68. Ibid. 
con unas instituciones y autonomía que serían fijadas por un futuro Parlament ${ }^{69}$. Pero sus esperanzas se vieron frustradas cuando Suárez decidió poner fin a estos proyectos. El buen resultado obtenido en Cataluña en el referéndum de la Ley para la Reforma Política hizo que Suárez, quien nunca había llegado a confiar plenamente en los planes respecto a Tarradellas, retomara la vía alternativa de los regímenes administrativos especiales. Esto permitió que el 18 de febrero de 1977 naciera el Consejo General de Catalunya que, de hecho, era «la reconstitución de la antigua Mancomunitat de principios de siglo» ${ }^{70}$. Suárez confiaba que, en un futuro, dicho organismo fuera controlado por Juan Antonio Samarach, presidente de la diputación provincial de Barcelona, quien estaba tratando de articular, junto a un grupo de alcaldes, una formación política centrista que pudiera servir de apoyo a Suárez en Cataluña ante unos futuros comicios.

El nuevo Consejo General de Catalunya fue frontalmente rechazado por Osorio, quien lamentaba se hubiera desaprovechado la oportunidad de restaurar la Generalitat a través de Tarradellas. Como señala Sánchez-Terán en sus memorias, «Suárez no dio vía libre a este proyecto de negociación y el asunto quedó congelado, a pesar de la insistencia de Osorio en la importancia política de la operación", pues durante los siguientes meses el vicepresidente continuó presionando al respecto ${ }^{71}$. Osorio realizó, sin éxito, diversos intentos por ganarse el apoyo de Rodolfo Martín Villa, y continuó sus contactos con miembros de la burguesía catalana. El 4 de febrero se había vuelto a reunir con Ortínez, quien escribió al presidente Suárez para insistirle sobre la conveniencia de proceder a la operación Tarradellas. Ortínez le indicaba:

El catalán no es violento por naturaleza, pero la frustración política puede crear un sentimiento negativo adicional al conjunto de complejos — de superioridad e inferioridad simultáneos- que aquel pueblo padece y puede llevar a producir una desorbitada reacción emocional, de cualquier signo, por ejemplo, de signo republicano ${ }^{72}$.

Esto le llevaba a reiterar a Suárez su propuesta centrada en el

reconocimiento de una nueva Generalitat creada, sin funciones ni contenido, con una presidencia provisional, como contrapartida al acatamiento de la Monarquía y su aceptación como el régimen del futuro. Es decir, sumar Cataluña a la Monarquía, con una contrapartida que consiste en reconocer el principio de autonomía, el contenido del cual decidirá el futuro Parlament ${ }^{73}$.

69. Ibid.

70. RIQUER, Borja de: «La configuración del sistema autonómico. El caso de Catalunya». En: TUSELL, Javier, y SOTO, Álvaro (eds.): Historia de la transición 1975-1986. Madrid: Alianza, 1996, p. 474.

71. SÁNCHEZ-TERÁN, Salvador: De Franco a la Generalitat. Planeta: Barcelona, 1988, p. 283.

72. AAO: Carta de Manuel Ortínez a Adolfo Suárez, 17 de febrero de 1977.

73. Ibid. 

EN LOS PRIMEROS GOBIERNOS DE LA TRANSICIÓN

Así consideraban, tanto Osorio como Ortínez, «sería posible arreglar el problema hoy, de forma positiva e inmediata para poder ofrecer una Cataluña monárquica y constructiva", pues detrás se encontraba el objetivo constante de sumar esta región a la Corona a través de la Generalitat ${ }^{74}$. Cuando Osorio preguntó a Suárez por dicha carta, el presidente le indicó que él tenía mejor información sobre Cataluña, resistiéndose nuevamente a los planes en torno a Tarradellas. Aun así, Osorio mantuvo sus contactos en favor de la operación y, el 21 de marzo, acompañado de Ortínez, se reunió nuevamente con Joan Mas Cantí y Carlos Güel, a los que se sumó Carlos Ferrer Salat. Estos le pidieron reactivar la operación, pero cuando se lo transmitió a Suárez, este insistió en que «estos, como Manuel Ortínez, representan la opinión de un sector de la burguesía catalana", desechando tales planteamientos al confiar en el éxito que la UCD tendría en los futuros comicios, aspirando a una mayoría absoluta a nivel nacional y a una victoria en las provincias catalanas que le permitieran fortalecer su Consejo General de Catalunya ${ }^{75}$. Como señaló Paul Preston, "fue típico de un ex franquista castellano el interpretar erróneamente la importancia que atribuyen los catalanes al simbolismo de la Generalitat ${ }^{76}$.

Osorio mostraba serias dudas sobre las previsiones de Suárez, especialmente con el resultado en Cataluña, dada la existencia de otra candidatura centrista liderada por Antón Cañellas, y la decisión de Samarach de no concurrir a las elecciones, lo que dejó la UCD catalana en manos de unos menos populares Carlos Sentís y Manuel Jiménez de Parga. El 25 de mayo, Ortínez escribió a Osorio para indicarle que «es difícil que la opción de Unión de Centro tenga éxito y es lamentable porque era fácil lograrlo», dudando que los planes de Suárez tuvieran éxito, por lo que avisaba que «el principio de autonomía, la Generalitat y su presidente se mantendrán y es posible que se hagan apremiantes después de las elecciones» ${ }^{77}$. El 15 de junio, día de las elecciones, Osorio se puso en contacto con Ortínez para expresarle que «todo lo que no hagamos antes de la constitución de las nuevas Cortes será tiempo perdido", exponiendo su temor ante el previsible triunfo en Cataluña de opciones de izquierda y nacionalistas, lo que provocaría que el reformismo perdiera el control del proceso. Sus miedos se vieron confirmados una vez se conoció el resultado electoral, con una UCD que, pese a su victoria nacional, no había conseguido la deseada mayoría absoluta, y en Cataluña había obtenido un mal resultado frente a la victoria cosechada por los socialistas. El 17 de junio, el líder socialista Joan Reventós anunció la constitución de una Asamblea de Parlamentarios, cuyo primer objetivo era elegir una comisión, que él presidiría, y apeló

74. Ibid.

75. OSORIO, Alfonso: Trayectoria política ... op.cit., p. 326.

76. PRESTON, Paul: El triunfo de la democracia en España: 1969-1982. Barcelona: Plaza y Janés, 1986, p. 159.

77. AAO: Carta de Manuel Ortínez a Alfonso Osorio, 25 de mayo de 1977. 
a un regreso meramente testimonial de Tarradellas para que delegase su legitimidad histórica en la nueva asamblea. Esto facilitó que la operación se retomara definitivamente al sumarse los intereses de Tarradellas y Suárez, quien frustradas sus expectativas vio en el viejo político la única posibilidad de evitar el control por parte de la izquierda y los nacionalistas del proceso catalán.

El 27 de junio de 1977, Tarradellas fue recibido en la Moncloa por Adolfo Suárez, pero, para entonces, Osorio ya había decidido abandonar el gobierno. Ortínez le envió entonces una carta para indicarle que

en el momento de tu cese quiero hacerte constar mi agradecimiento por las atenciones y amabilidades que tuviste conmigo. Te agradezco sobre todo la atención y el cuidado que pusiste en escuchar el tema que, estos días precisamente, estalló como el de gran actualidad, es decir, el del presidente de la Generalitat ${ }^{78}$.

Proseguía Ortínez diciendo que, pese a finalmente haberse dado «una excesiva capitalización por parte de la UCD", "puedes estar satisfecho de tu labor, de la que puede decirse, con toda razón, ha sido coronado por un éxito rotundo» ${ }^{79}$. Pero los partidos habían acabado capitalizando parte de la operación, que perdió ese valor simbólico con el que Ortínez y Osorio habían pretendido vincular esta región al Estado a través de la Corona. Como se afligía Ortínez en sus memorias, "aquello que se había planteado desde el primer momento como una operación de Estado entre la Monarquía española y la Generalitat, entre dos instituciones, rebajaba su nivel y se convertía en una operación de Gobierno y en un intento de operación de partido» ${ }^{80}$. Pese a todo, la vuelta de Tarradellas se había logrado, aunque Osorio lamentaba que se hiciera demasiado tarde. Fue el 23 de octubre cuando, finalmente, Tarradellas regresó a Barcelona, escribiendo un telegrama a Osorio para indicarle: "Reciba sincero agradecimiento por su extraordinaria contribución trascendental restablecimiento autonomía con mi mayor afecto» ${ }^{81}$.

Para entonces, hacía meses que Osorio había abandonado sus responsabilidades gubernamentales. Las diferencias políticas con Suárez, principalmente respecto a la forma en que debía abordarse el problema territorial, habían resultado más que evidentes. Suárez había preferido relegar la cuestión a la espera de una nueva Constitución, mientras Osorio, desde su visión «neoforalista», interpretaba que no afrontar el tema de forma directa, fundamentalmente en lo referido a las peculiaridades catalana y vasca, quitaría valor simbólico al tratamiento de estos casos, privando al gobierno de un control más riguroso de la descentralización regional ante el inminente proceso constituyente ${ }^{82}$.

\footnotetext{
78. AAO: Carta de Manuel Ortínez a Alfonso Osorio, 27 de junio de 1977.

79. AAO: Ibid, y carta de Manuel Ortínez a Alfonso Osorio, 7 de julio de 1977.

80. ORTÍNEZ, Manuel: Una vida entre burgesos. Barcelona: Ediciones 62, 1993, p. 150.

81. AAO: Telegrama de Josep Tarradellas a Alfonso Osorio, 10 de octubre de 1977.

82. PRESTON, Paul: ...op.cit., p. 159.
} 

EN LOS PRIMEROS GOBIERNOS DE LA TRANSICIÓN

\section{UnA VISIÓN DE EsPaña desde la CONSTITUCión}

Para concluir este acercamiento a la idea de España de Alfonso Osorio, se apuntará brevemente la actuación y posiciones que adoptó una vez abandonó el consejo de ministros, expuestas someramente al no tratarse del eje central de la investigación.

Durante la denominada legislatura constituyente, Alfonso Osorio fue nombrado senador de designación real, formando en el Senado un Grupo Parlamentario Independiente (GPI) junto a otros senadores reales, pues para entonces ya había roto definitivamente relaciones con Suárez y la UCD ${ }^{83}$. Debido a esa cierta condición de senador independiente, su aportación al proceso constitucional fue reducida, ante una labor desarrollada de forma mayoritaria por el Congreso de los Diputados — frente al año empleado por la Cámara Baja para discutir la nueva Constitución, los debates del Senado apenas alcanzaron los dos meses-, y capitalizada por las dos grandes formaciones políticas en torno a un texto consensuado, en el cual trataron de evitar la introducción de modificaciones significativas por parte de figuras no controladas, siendo este el caso de los senadores reales como Osorio ${ }^{84}$. Sin embargo, el exvicepresidente tendría ocasión de realizar una intervención relevante cuando, de forma inesperada, el asunto vasco estalló en el Senado. Si el tema catalán se había solventado con el restablecimiento de la Generalitat y la introducción en la Constitución del concepto de nacionalidades — respecto al que Osorio mostró públicamente su oposición-, las posiciones soberanistas vascas no habían encontrado el encuadre adecuado. Esta cuestión trató de solventarse desde el Congreso a través de la Disposición Adicional Primera, por la cual se reconocía que "la Constitución ampara y respeta los derechos históricos de los territorios forales», con la cual se perseguía la incorporación del Partido Nacionalista Vasco (PNV) al consenso constitucional. Sin embargo, los nacionalistas vascos habían demandado que el texto indicase que la Constitución "reconoce y garantiza" dichos derechos, otorgando a sus peculiaridades foralistas un carácter de acuerdo político previo a la Constitución ${ }^{85}$. Ante el rechazo gubernamental a tales cesiones, y la dificultad de satisfacer las demandas del PNV, la fórmula inicial fue asumida por las grandes fuerzas políticas nacionales del Congreso, pero, al llegar al Senado, los nacionalistas vascos lograron que su propuesta saliera adelante con la solidaridad de diversos senadores reales. El gobierno no tardó en actuar para frenar los planteamientos peneuvistas.

83. Los senadores miembros del GPI eran Luis Díez-Alegría, Alfonso Escámez, Guillermo Luca de Tena, Luis Olarra, Alfonso Osorio, Manuel Prado y Colón de Carvajal, Miguel Primo de Rivera, Andrés Ribera, Luis Sánchez Agesta y Fermín Zelada.

84. SOTO, Álvaro: «El Senado en la transición democrática». En: PÉREZ, Manuel (Coord.): El Senado en la Historia. Madrid: Temas del Senado, 1998, pp. 419-479.

85. MONREAL, Gregorio: "La disposición adicional primera de la Constitución de 1978 en las Cortes", Iura Vasconiae, 11, 2014, p. 319. 

EN LOS PRIMEROS GOBIERNOS DE LA TRANSICIÓN

Ante ese desencuentro, Mikel Unzueta, portavoz del Grupo de Senadores Vascos, decidió recurrir a Osorio, de quien conocía su simpatía hacia sus tesis y esperaba que, debido a su prestigio político como exvicepresidente, lograra alcanzar una fórmula de consenso que pudiera ser aceptado por todos los grupos. Osorio escribió su propia propuesta, la cual decía:

Los derechos históricos de los territorios forales abolidos por las leyes del 25 de octubre de 1839 y del 21 de julio de 1876 y demás disposiciones concordantes, se reintegrarán actualizados en el estatuto de autonomía que se elabore por acuerdo entre las instituciones representativas de dichos territorios y el Gobierno.

El Estatuto de Autonomía a que se refiere el párrafo anterior será sometido a referéndum de los territorios afectados y al voto de las Cortes Generales, y, en caso de ser ulteriormente aprobado, será promulgado como ley. Su modificación se ajustará a este mismo procedimiento.

En ningún caso podrá ser lesionada la foralidad actualmente vigente de Álava y de Navarra $^{86}$.

Su fórmula reconocía claramente la existencia de unos derechos históricos del pueblo vasco, pero eludía cualquier tipo de referencia a su encuadre y vinculación con la Constitución, fuente de la disputa, y hacía en cambio una mención directa al estatuto de autonomía de que debía dotarse dicho territorio en un futuro. Contando con el apoyo de su grupo parlamentario, Osorio afirmaba que «me acerqué al Grupo de Senadores Vascos, que cuando entré estaban rezando el rosario", para proponerles dicho texto, el cual habrían aceptado ${ }^{87}$. Según su relato, también llamó a Sabino Fernández Campo, secretario de la Casa del Rey, para conocer la opinión del monarca, quien se habría mostrado favorable. Igualmente, se lo habría planteado a Antonio Jiménez Blanco, portavoz centrista en el Senado, quien también aceptó su propuesta ${ }^{88}$. Sin embargo, dicha fórmula no llegó a tramitarse debido a la orden dada por el entonces vicepresidente del Gobierno, Fernando Abril Martorell, quien era contrario a que se admitiera dicho enunciado y promovió la recuperación de la redacción inicial. Osorio consideraba que, tras el rechazo a su propuesta, subyacía una cuestión personal, pues «cuando Fernando vio que la enmienda era mía porque estaba redactada a mano, y se dio cuenta de que era mi letra, dijo que ni hablar. Fernando estaba cabreado porque no me había hecho de UCD ${ }^{89}$. No obstante, las razones esgrimidas por el vicepresidente Abril, y respaldadas por el propio Adolfo Suárez, pasaban por oponerse a cualquier planteamiento como el sugerido por Osorio, que consideraban carente de la suficiente claridad respecto a la relación establecida entre los derechos históricos reivindicados y

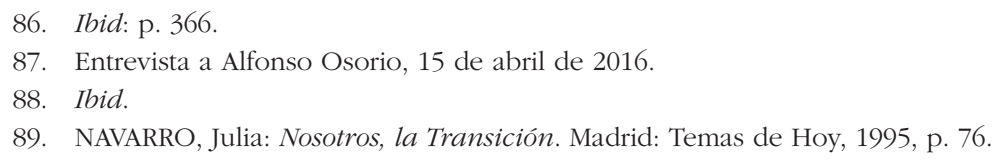



EN LOS PRIMEROS GOBIERNOS DE LA TRANSICIÓN

su sujeción a la nueva Carta Magna, temiendo que pudiera dar lugar a que los nacionalistas vascos apelaran a unos derechos y una soberanía ubicados al margen de la Constitución y de la propia soberanía nacional ${ }^{90}$. Además, el gobierno lo consideraba especialmente arriesgado, dada la ambigüedad mostrada por el PNV respecto al derecho de autodeterminación ${ }^{91}$. Cuando el texto original respaldado por el Gobierno fue votado por el Senado, se aprobó con el rechazo del PNV y la abstención de diversos senadores, entre ellos Osorio, quien consideró erróneo no realizar un reconocimiento expreso de la legitimidad de los derechos históricos vascos pues, en su criterio, era la vía para desplazar al PNV de cualquier posible simpatía con la idea de autodeterminación, que estimaba alejada de la tradición histórica del nacionalismo vasco.

Aunque Osorio consideró el resultado general de la Constitución como satisfactorio, en lo relativo al Título VIII, sobre la organización territorial del Estado, se mostró abiertamente crítico, y en una conferencia pronunciada en el Club Siglo XXI en diciembre de 1980 no dudó en rechazar «la ambigüedad y la ambivalencia» de dicho título ${ }^{92}$. Sobre el modelo territorial surgido, mostró su rechazo al término nacionalidades, sólo dispuesto a aceptar la existencia de regiones, y criticó el modelo de "café para todos», que estableció un sistema de regiones con autonomías equivalentes. Este modelo, impulsado desde UCD por Manuel Clavero Arévalo como forma de generalizar una descentralización que "rebajara» una singularidad vasco-catalana que pudiera derivar en privilegios, fue abiertamente criticado por el exvicepresidente, que estimaba necesario precisar «con exactitud si los pequeños particularismos localistas no están interfiriendo gravemente en una ordenación lógica de la Nación y del Estado», debiendo afrontar de forma eficaz el asunto autonómico para dar lugar a «las Comunidades autónomas razonables y posibles»33. Para Osorio, el problema partía de aquellos primeros gobiernos de la Transición que nunca tuvieron un programa lo suficientemente preciso al respecto, algo que se prolongó al período constituyente. En este nuevo contexto, llegó a plantear que solo existían dos opciones, «dar marcha atrás, con todas las consecuencias, reformando la Constitución y su título VIII para volver a reiniciar el camino, o

90. LAMELAS, Antonio: La Transición en Abril. Biografía politica de Fernando Abril Martorell. Barcelona: Ariel, 2004, pp. 219-226.

91. El PNV se encontraba dividido respecto al problema de la autodeterminación. Ante la enmienda presentada al respecto por Euskadi Ezkerra, una figura del PNV tan destacada como Xavier Arzalluz no dudó en catalogarlo de "virguerías trotskistas, nosotros estamos por la vía foral»; mientras otros representantes del partido consideraban difícil oponerse a un derecho que estimaban previo a cualquier Constitución. Véase: ÁLVAREZ JUNCO, José: "La idea de España en el sistema autonómico». En: MORALES, Antonio, FUSI, Juan Pablo, DE BLAS, Andrés (Coords.): Historia de la nación y el nacionalismo español. Madrid: Galaxia Gutenberg, 2013, pp. 809-839.

92. Conferencia "Una idea del Estado», disponible en OSORIO, Alfonso: Escrito desde...op.cit., pp. 189-207.

93. Ibid. 
afrontar con toda claridad y con todas las consecuencias la organización federativa, aunque no federal, del Estado» ${ }^{94}$. Llegó incluso a plantear la posibilidad, en contra de lo mantenido previamente, de articular una Hacienda Regional y establecer un modelo de conciertos económicos generales, de modo similar al planteado por José Calvo Sotelo en el Estatuto Provincial de 1925, así como la creación de un Consejo de presidentes de Comunidades Autónomas bajo la dirección del presidente del Gobierno ${ }^{95}$.

Dichas posturas, referidas en un contexto de profunda crisis política, no tardaron en diluirse para retomar sus tradicionales ideas de que «Cataluña y el País Vasco necesitaban, de alguna manera, un tratamiento especial» ${ }^{96}$. No resulta extraño comprender sus posteriores críticas hacia la LOAPA (Ley Orgánica de Armonización del Proceso Autonómico) que, aprobada en 1982 tras un acuerdo entre UCD y PSOE, permitió generalizar y equiparar el modelo autonómico, diluyéndose las diferencias de aquellas regiones con una tradición y singularidades propias, lo que en su opinión provocó que estas aumentaran sus reivindicaciones. Para algunos, el avance hacia tales demandas parecía inevitable, puesto que nacionalistas vascos y catalanes hubieran considerado insuficiente toda concesión en busca de un constante aumento de sus competencias; otros, como el propio Osorio, consideraron que fue precisamente el no reconocimiento de sus singularidades frente a otras regiones lo que dio lugar a un aumento de sus reivindicaciones identitarias, lo que "ha producido un espiral que nunca tiene fin» ${ }^{97}$.

\section{CONClusión}

La idea de España mantenida por Alfonso Osorio, que a lo largo de estas páginas ha sido referida como "neoforalista", partía de una visión historicista nutrida de los planteamientos tradicionalistas expuestos en el pasado por Juan Vázquez de Mella, una referencia constante en la construcción de su proyecto regional. Esta aproximación ideológica a planteamientos tradicionalistas, pese a su incuestionable relación política con los sectores católicos, se debía a los vínculos biográficos y emocionales que el santanderino tenía con el entorno tradicionalista, reflejo de cómo la propia experiencia vital influye en la idea y proyección de la nación. Osorio defendió una organización territorial del Estado basada en las singularidades históricas, lo que le llevó a confrontar con las tesis funcionalistas enunciadas por determinados sectores de la política tardofranquista. Osorio proyectaba una generalización del hecho regional, aunque con una especial atención a los territorios con unas peculiaridades propias que debieran

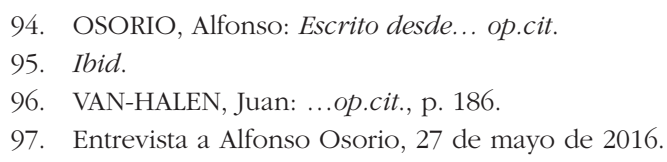



EN LOS PRIMEROS GOBIERNOS DE LA TRANSICIÓN

ser reconocidas, refiriéndose a la exigencia de atender, en un primer momento, las diferentes demandas procedentes de las provincias vascas y Cataluña.

Durante el primer gobierno de Adolfo Suárez, entre julio de 1976 y las primeras elecciones democráticas, Osorio fue el miembro del ejecutivo que dedicó mayores esfuerzos y mantuvo unos postulados más definidos sobre la necesidad hacer frente al problema territorial del Estado. Esto se debía a la convicción desarrollada desde esos parámetros «neoforalistas», así como al temor a que el reformismo perdiera el control sobre el proceso y dejara de ser quien marcara el ritmo del cambio político, debiendo hacer concesiones a una oposición situada en planteamientos federales. Los amplios esfuerzos de Osorio para impulsar medidas políticas acordes con sus postulados chocaron con la posición del presidente Suárez, situado en un nacionalismo español regionalizado que, si bien apelaba a las regiones, carecía de un proyecto político al respecto, estando dispuesto a moverse en un ámbito más pragmático que doctrinal, de forma contraria a su vicepresidente. Además, los esfuerzos del Presidente se centraron en la democratización de las instituciones y la celebración de unas elecciones libres, lo que, de algún modo, le obligó a postergar el problema territorial. Esta diferencia fue causa de choque constante entre ambos, lo que supuso una cuestión clave en su distanciamiento político, existiendo también otras diferencias que no han podido ser abordadas en este artículo. No obstante, en el pensamiento de Osorio y sus diversas iniciativas estuvieron ya presentes lo que serían las grandes cuestiones territoriales que debieron abordarse en un futuro inmediato: la devolución de los derechos forales a las provincias vascas y la restauración de la Generalitat de Cataluña. Su postergación impidió que la actuación al respecto fuera canalizada por el Estado a través de la Corona, siempre presente en las tesis de Osorio como elemento vertebrador de las regiones bajo la fórmula de una monarquía federativa, debiéndose retrasar a un debate constitucional donde las demandas e intereses de los partidos dificultaron un ya de por si complejo escenario, el cual derivó en la instauración del Estado de las Autonomías y el denominado "café para todos".

El resultado obtenido fue abiertamente criticado por Osorio debido a una generalización homogénea del modelo descentralizador, rompiendo con su defensa del reconocimiento de las peculiaridades de cada región según su historia. Osorio mantuvo siempre que el conflicto nació, precisamente, en aquel primer gobierno de Suárez que no afrontó el hecho regional, pues si se hubieran dado salida a las demandas más claras, como eras las procedentes de las provincias vascas y Cataluña, creía que Suárez habría podido controlar el proceso de descentralización y, quizá, hubiera contenido las reivindicaciones de autonomía de otros territorios sin las raíces históricas suficientes desde su idea de España. 